\title{
PROGRESS WITH A GENERAL CATALOGUE OF POSITIONS AND ABSOLUTE PROPER MOTIONS BASED ON AGK 2, AGK 3 AND THE ASTROGRAPHIC CATALOGUE AS SOURCES OF DATA
}

\author{
W. Dieckvoss \\ Hamburger Sternwarte
}

In Hamburg we have the catalogue AGK 3 and a revised AGK 2 for the declination zones $+1^{\circ}$ to $+18^{\circ},+24^{\circ}$ to $+89^{\circ}$ on magnetic tapes, in manuscript and on punched cards. The remaining zones are in preparation. At the present time (March 1970) the catalogue, on account of some deficiencies, is not in the proper shape for a universal publication. A. Günther and H.Kox (1970) since 1967 investigated the zones Greenwich, Rome-Vatican, Catania and Helsingfors of the Astrographic Catalogue ( $A C$ ) using the AGK 2/3 data as source for reference stars' positions. The original rectangular coordinates $x, y$ for each of the plates together with AGK2 numbers are on tapes. By applying the systematic corrections derived by Günther and Kox and by using the new, definitive plate constants derived in course of the work on the $\mathrm{AC}$-zones the $\mathrm{x}, \mathrm{y}$ can be transformed into spherical coordinates reffered to the equinox 1950.0 and in the FK4 system. This was done in the last few months, and arithmetic means were produced for the individual stars with AGK 2 numbers for reference number. Simultaneously the mean square errors (mse) were derived when two or more plates went into the means. Table 1 gives values for average values of the mse, as an example for always two observations.

\section{Table 1}

Average values of mean errors of positions from the mean of two neighboring plates.

$\begin{array}{lcrr}\text { Decl. Zone } & \text { AC } & \text { m.s.e. } \\ 40^{\circ} \text { to } 45^{\circ} & \text { Hels. } & \pm 0 . ' 14 \\ 47 & 53 & \text { Cat. } & 0.22 \\ 55 & 63 & \text { Vat. } & 0.32 \\ 65 & 90 & \text { Grw. } & 0.19\end{array}$

The next step in forming a zone catalogue of positions and proper motions consisted of combining the three positions from AGK3, AGK2, AC applying Newcomb's (1906) method of the central date. Evaluation of the mse of the different sources is of special importance. In AGK 3 and AGK 2 these mse were adopted to be \pm 0 !' 18 and \pm 0 "'15 for two observations. The actual values for each star are calculated according to the number of observations involved. 
For the AC corresponding to Table 1 the mse depend on zone of declination.

The catalogue thus produced gives the number from the Bonner Durchmusterung (BD) as reference number, magnitude (from AGK2), spectral type, RA and Decl. 1950.0 FK4-system, central epoch, proper motion components ( $\mathrm{pm}$ ) in RA both in $\mathrm{s} / \mathrm{yr}$ and in "/yr after multiplication by cos (Decl.), in Decl. in "/yr, mse of position and of $\mathrm{pm}$. Position and $\mathrm{pm}$ are not correlated, the epoch is the epoch of maximum weight of position according to the method applied. Table 2 indicates typical values for two selected zones of different overall quality.

\section{Table 2}

Cental Epoch $t_{0}$ and mean errors of positions and proper motions
derived from AGK $2 / 3, \mathrm{AC}$.

$\begin{array}{cccccc}\text { BD-Zone } & \text { AC } & t_{0} & \text { position } & \begin{array}{c}\text { m.s.e. of } \\ \text { pr.motion }\end{array} & \text { pos. } 1980 \\ & & & & & \\ +43^{\circ} & \text { Hels } & 1920 & \pm 0 ! \cdot 09 & \pm 0 ! \cdot 004 / \mathrm{yr} & \pm 0 ! 26 \\ +56 & \text { Vat. } & 1935 & 0.10 & 0.006 & 0.29\end{array}$

An idea presented at the Tampa Conference on Photographic Astrometric Technique in 1968 (Dieckvoss, 1970) calls for extrapolation to the epoch of old catalogues in order to derive systematic corrections depending on RA, Decl. , magnitude, and subsequently to add the data to the zone catalogue while retaining the noncorrelation of position and pm. (Cp. B. Boss, 1937, A. Reiz, 1957, H. Eichhorn and W. D. Googe, 1969). As a test the relatively bad zone $+56^{\circ},+57^{\circ}$ was selected, and of two old catalogues: AGK 1 Helsingfors-Gotha, Yale Trans. 7 (epochs 1870, 1916 respectively) the data for $5^{h}$ to $7^{h}$ and $17^{h}$ to $19^{h}$ RA were punched on cards.

The differences in the sense new zone catalogue minus additional catalogue after proper updating to the equinox of 1950 (including in AGK1 the change from Struve's to Newcomb's constant of procession) was sorted according to full hours of RA and degrees of Decl. The deviation from the mean values were taken as anindication of the mse of the differences. By eliminating the mse of the extrapolated zone catalogue positions the mse of the additional catalogue was calculated. After applying the corrections the differences were sorted according to magnitude. Here no significant runs could be established on account of the scarce number of stars for each group. In practice later on use of the method published by P. Brosche (1966) is indicated. Table 3 shows the results, and the mse of the old positions for two observations. 
Table 3

Sample Systematic Corrections to old Catalogues

\begin{tabular}{|c|c|c|c|c|c|}
\hline \multirow{2}{*}{$\begin{array}{l}\text { Decl. } \\
+56^{\circ}\end{array}$} & \multirow{2}{*}{$\begin{array}{c}\mathrm{RA} \\
\mathrm{h}_{5} \\
6.5\end{array}$} & AGK 1 & $\begin{array}{l}1 \\
-G .\end{array}$ & \multicolumn{2}{|c|}{$\begin{array}{c}\text { Yale } \\
\text { Trans. } \underline{7}\end{array}$} \\
\hline & & -0.080 & $0: 400$ & -0.133 & $-0 ! ! 30$ \\
\hline & $\begin{array}{r}6.5 \\
17.5\end{array}$ & $\begin{array}{l}-0.080 \\
-0.033\end{array}$ & $\begin{array}{r}0.00 \\
-0.20\end{array}$ & $\begin{array}{l}-0.127 \\
-0.173\end{array}$ & $\begin{array}{l}-0.25 \\
-0.05\end{array}$ \\
\hline & 18.5 & -0.033 & -0.20 & -0.160 & -0.10 \\
\hline$+57^{\circ}$ & 5.5 & -0.080 & 0.00 & -0.133 & -0.30 \\
\hline & 6.5 & -0.080 & 0.00 & -0.127 & -0.25 \\
\hline & 17.5 & -0.033 & -0.20 & -0.173 & -0.05 \\
\hline & 18.5 & -0.033 & -0.20 & -0.160 & -0.10 \\
\hline
\end{tabular}

mean error for two observations $\quad \pm 0 ! \cdot 70 \quad \pm 0 ! 26$

By adding first AGK1, then Yale 7 the epochs shifted from 1936 to 1934 and 1932 approximately. Here the very low weight of the AGK 1 and the late epoch of the Yale catalogue are responsible for the low rate of improvement. The weight of the position increased only by small amounts, the mse of the pm decreased, as can be seen in Table 4.

A further simulated new position for the epoch 1970 with three observations leading to a mse of \pm 0 "' 14 was added as a test. At last the mse of position, extrapolated to 1980 , was tabulated.

\section{Table 4}

Epochs and Root Mean Square Errors (mse) for a Sample at $+56^{\circ}$ and $+57^{\circ}$ Declination

\begin{tabular}{|c|c|c|c|c|}
\hline Column & 1 & 2 & 3 & 4 \\
\hline $\begin{array}{l}\text { Catalogues } \\
\text { involved }\end{array}$ & $\begin{array}{c}\text { AGK } 3 \\
\text { AGK } 2 \\
\text { AC }\end{array}$ & $\begin{array}{c}\text { Col. } 1 \\
+ \\
\text { AGK 1: } \\
\text { Hels. -G }\end{array}$ & $\begin{array}{c}\text { Col. } 2 \\
+ \\
\text { Yale } \\
\text { Tr. } 7\end{array}$ & $\begin{array}{c}\text { Col. } 3 \\
+ \\
\text { New Obs. } \\
1970\end{array}$ \\
\hline Central Epoch & 1935 & 1934 & 1932 & 1944 \\
\hline $\begin{array}{l}\text { Position } \pm \text { !"01.. } \\
\text { Motion }\end{array}$ & 10 & 10 & 9 & 8 \\
\hline $\begin{array}{l} \pm ! 001 / \mathrm{yr} . . . . . \\
\mathrm{n} \text { at Epoch }\end{array}$ & 6 & 5 & 5 & 3 \\
\hline $1980 \pm ! 01 \ldots \ldots$ & 29 & 26 & 26 & 14 \\
\hline
\end{tabular}


A wholesale evaluation of the AGK3, AGK2, and AC data + old catalogues is more than the Hamburg Observatory can handle at the present time. A bigger institution with the necessary team of scientists and with sufficient computer facilities should do the work. We shall start collaboration with the photogrammetric department of the Technical University Stuttgart in the near future.

In principle any new plate with a wide angle lens of good astrometric quality could be used without new reference positions, the measures could be put into the overall reference system built up from a combination of the three basic catalogues.

In conclusion I should like to express a warning: the method sketched here seems to require only some computing time, some extra work of transforming catalogues into machine-readable form, some care in studying large residuals or unduly large discrepancies for individual stars. Everybody may be happy with a big catalogue and proper motions in a well defined coordinate system, abolishing for some time the necessity to go on with meridian work. In reality the overall FK4-system is not well represented in each individual small field in the sky. The systematic part in the positions of AGK2 and AGK3 can be estimated without much reasoning to be comparable to the mse of the zero-point of each plate. The uncertainty of this zero-point is of the order of $\pm 0: ' 05$. Extrapolation from 1930 and 1960 to 1900 or 1990 then leads to values of $\pm 0 ! 11$, and the smallness of values of random errors is not correlated with systematic fluctuations in the sky as covered by this zone work.

New reduction of the data by overlap-methods, planned in collaboration with the team at Stuttgart, probably will help, as well as the work being done by P. Lacroute of Strasbourg.

\section{References}

Boss, B. , 1937, General Catalogue, Washington, D. C. , Vol. 1, p. 49. Brosche, P., 1966, Veröff. Astron. Rechen-Institut Heidelberg, 2, No. 17. Dieckvoss, W. , 1970, in print.

Eichhorn, H. , Googe, W. D. , 1969, Aston. Nachr. 291, 125.

Günther, A., Kox, H. , 1970, Astron. and Astrophys. 4, 156.

Newcomb, S. , 1906, A Compendium of Spherical Astrōnomy, Par.40, Dover Publ. New York, 1960.

Riez, A. , 1957, Ann. Obs. Lund No. 14, p,4 (here the last formula contains an obvious error). 